\title{
Menggapai Permainan Tradisional Anak Indonesia Dalam Perangkat Berbasis Android
}

\author{
Sri Handayani \\ (sri@usm.ac.id) \\ (Program Studi Teknik Informatika)
}

\begin{abstract}
Play is a child's world, by playing the child will learn to interact, learn to share, emotion and hone motor skills that support the development of the child. Game in the era of information technology is a game that does not require a lot of movement and tend to release attachment to the neighborhood children and their parents. While traditional games children Indonesia offered Android-based devices today is still an application to introduce the history of the game and how to play. This app only provides information, has not been able to replace the benefits and functions of traditional games of Indonesian children the truth.Indonesian traditional games children a heritage, a legacy of the ancestors of Indonesia. So as to preserve the cultural ancestry as means of Indonesian children were able to preserve the culture of Indonesia. But now it has changed the cultural inheritance child's play. Culture plays a passive child, and let go of attachment to the child with the parents and the environment.The biggest challenge will be faced in the future is how to implement actual meaning for children to play in Android-based devices.
\end{abstract}

Keywords : Traditional Toys, Children, Android

\section{Pendahuluan}

Apakah anak-anak yang hidup di era sekarang masih mengenal permainan dan lain-lain? Seberapa sering terlihat anak-anak di era sekarang memainkan permainan itu? Secara jujur, di lingkungan penulis sendiri saat ini sangat jarang menemui anak-anak yang memainkan permainan tradisional. Perkembangan teknologi informasi khususnya dengan adanya beragam perangkat berbasis Android yang menawarkan fitur permainan yang lebih modern membuat semua jenis permainan tradisional yang ada menjadi kurang diminati. Apalagi disertai dengan kemudahan pengguna mengakses games tersebut melalui perangkat berbasis android. Melihat fenomena seperti ini penulis selalu berfikir akankah permainan tradisional anak Indonesia akan tergantikan dengan permainan anak di perangkat berbasis Android? Seandainya itu terjadi sungguh miris kehidupan anak di masa depan. Karena dunia anak, adalah bermain. Saat anak bermain keterkaitan emosi dan lingkungan harus terlibat. Bermain bersama teman, membuat anak belajar berinteraksi, berbagi, dan belajar beremosi. Saat anak bermain butuh lingkungan untuk membuat kemampuan motoriknya berkembang.

Tidak dapat dipungkiri, anak-anak yang terlahir di era teknologi seperti saat ini sangat akrab dengan perangkat berbasis Android (smartphone, gadget) Tuntutan hidup ataupun kebutuhan hidup membuat setiap keluarga menggunakan perangkat berbasis Android untuk menopang aktifitas kehidupannya. Perangkat berbasis Android bukan hanya dapat digunakan untuk berkomunikasi (telepon, sms), dapat pula digunakan untuk berinteraksi membentuk komunitas melalui group aplikasi yang ditawarkan (line,wa, bbm, twitter) namun juga dapat digunakan untuk menjalankan bisnis (blog, 
website) dan juga untuk menambah pengetahuan dan informasi.

Kehadiran perangkat berbasis Android yang menawarkan spesifikasi terbaik dengan harga terjangkau di pasaran, tentu menjadi daya tarik konsumen untuk membeli perangkat tersebut yang dirasa memiliki banyak manfaat. Pola hidup yang telah menerapkan perangkat teknologi informasi dalam keseharian membuat anak-anak sudah terbiasa melihat, memegang, dan menggunakan perangkat berbasis Android. Saat seorang anak menangis, tanpa disadari perangkat berbasis Android sering digunakan untuk mengalihkan perhatian anak tersebut. Sejenak anak yang menangis bisa terdiam karena si anak sibuk dengan perangkat yang dipegangnya. Saat anak ini mulai dapat menggunakan perangkat berbasis Android ini, saat itulah dimulai kepekaan pada lingkungan sekitar akan berkurang, anak akan memilih asyik dengan aplikasi yang disediakan oleh orang tuanya. Sementara orang tua berfikir, anaknya tidak akan mengganggu aktifitasnya saat itu karena telah sibuk dengan dunia yang baru.

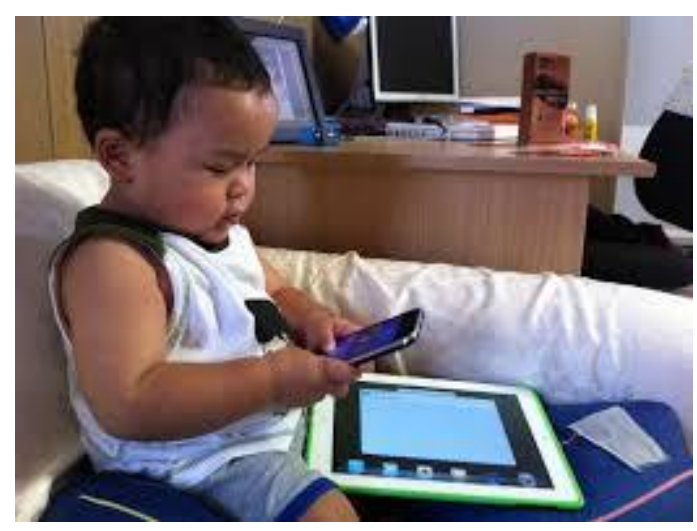

Gambar 1.1. Balita dengan perangkat berbasis Android

Dari penjelasan di atas, penulis tertarik untuk membahas tentang mampukah perangkat berbasis Android menyedia media bermain seperti permainan tradisional anak Indonesia, yang bukan hanya mampu melatih tumbuh kembang anak, mampu membuat anak belajar berinteraksi, belajar berbagi, belajar beremosi, dan mengembangkan kemampuan motoriknya.

\section{Pembahasan}

\section{Perkembangan Psikologi Anak}

Sejak berabad-abad yang lalu perhatian terhadap seluk-beluk kehidupan anak sudah diperlihatkan, sedikitnya dari sudut perkembangannya agar bisa mempengaruhi kehidupan anak ke arah kesejahteraan yang diharapkan. Anak harus tumbuh dan berkembang menjadi manusia dewasa yang baik yang bisa mengurus dirinya sendiri dan tidak bergantung atau menimbulkan masalah pada orang lain, pada keluarga atau masyarakatnya.

Banyak filsuf, dokter, ahli pendidikan dan ahli teologi memberikan pandangan mengenai anak dan latar belakang perkembangannya serta pengaruhpengaruh keturunan dan lingkungan hidup terhadap hidup kejiwaan anak. Pada akhir abad ke-17, seorang filsuf Inggris yang terkenal John Locke (1632-1704 ) mengemukakan bahwa pengalaman dan pendidikan bagi anak merupakan faktor yang paling menentukan dalam perkembangan anak. Locke mengemukakan istilah "tabula rasa' untuk mengungkapkan pentingnya pengaruh pengalaman dan lingkungan hidup terhadap perkembangan anak. Anak adalah pribadi yang masih bersih dan peka terhadap rangsangan yang berasal dari lingkungan ( Prof. Dr. Singgih D. Gunarsa, 1997 : 15-16) Lingkungan anak adalah lingkungan untuk bermain, dimana permainan yang biasa 
dimainkannya akan membentuk karakter dan kepribadian anak.

\section{Permainan Tradisional Anak Indonesia}

"Permainan" adalah sesuatu yang dimainkan; yang digunakan untuk bermain. Tradisional adalah berpegang teguh terhadap kebiasaan turun temurun ; Sikap dan cara berpikir serta bertindak yang selalu berpegang teguh pada norma dan adat kebiasaan yang secara turun temurun. Jadi arti dari permainan tradisional adalah suatu hal yang berhubungan dengan bermain yang sifatnya turun temurun atau warisan nenek moyang.

Permainan tradisional sebagian besar berupa permainan anak yang merupakan bagian dari folklore. Permainan tradisional adalah suatu hasil budaya masyarakat, yang berasal dari zaman yang sangat tua, yang telah tumbuh dan hidup hingga sekarang, dengan masyarakat pendukungnya yang terdiri atas tua muda, laki perempuan, kaya miskin, rakyat bangsawan dengan tiada bedanya. Permainan tradisional bukanlah hanya sekedar alat penghibur hati, sekedar penyegar pikiran atau sekedar sarana berolah raga tetapi memiliki berbagai latar belakang yang bercorak rekreatif, kompetitif, paedogogis, magis dan religius. Permainan tradisional juga menjadikan orang bersifat terampil, ulet, cekatan, tangkas dan lain sebagainya ( Drs. Ahmad Yunus, 1980 / 1981 ). Jadi dapat disimpulkan bahwa permainan tradisional adalah suatu permainan warisan dari nenek moyang yang wajib dan perlu dilestarikan sebagai bagian dari proses perkembangan anak.
Jenis-jenis Permainan Tradisional Jenis-jenis permainan tradisional yang masih dikenal masyarakat setempat dan yang diantaranya masih dijumpai di beberapa perkampungan. Berikut ini jenis-jenis permainan tradisional, diantaranya yaitu:

\section{Sepak bola}

Permainan yang menggunakan bola, biasanya dilakukan beramai -ramai dan dilakukan di tanah lapang atau tanah kosong.

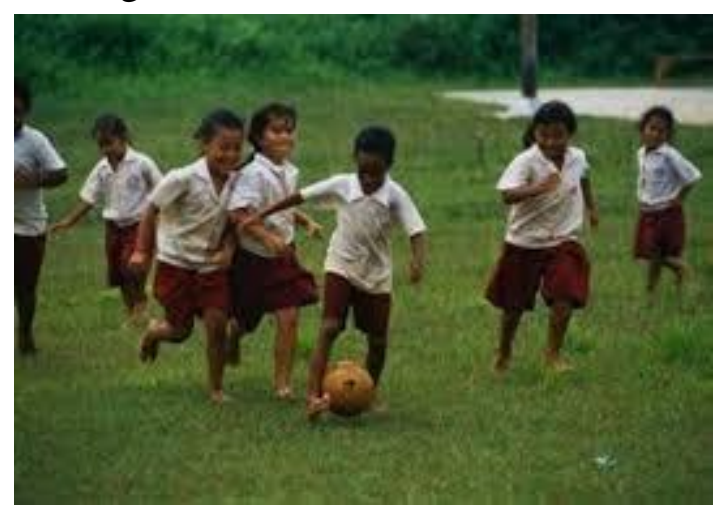

2. Bekel

Permainan yang menggunakan bola kecil dari karet, yang dimainkan berdasarkan kecepatan dan ketrampilan tangan anak-anak. Dilakukan berkelompok di pelataran rumah ataupun di ruangan.

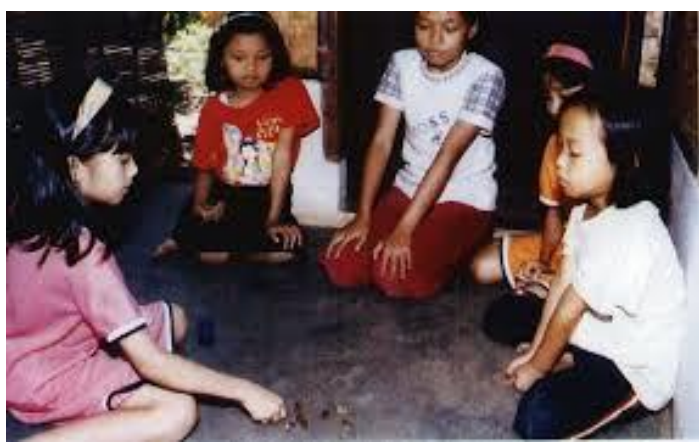

Gambar 2.2. Anak-anak bermain bekel

\section{Congklak}


Permainan yang memasukkan biji-biji kedalam kayu coklak, biasanya dilakukan oleh dua orang yang bermain secara bergantian.

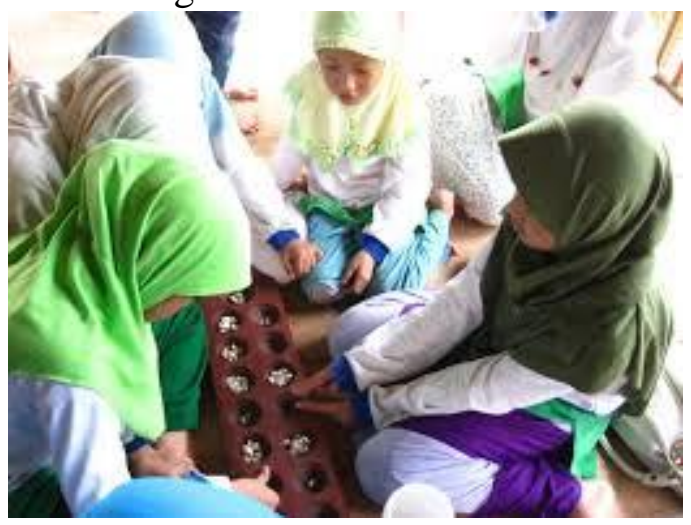

Gambar 2.3. Anak-anak bermain congklak

\section{Lompat tali}

Permainan yang menggerakan tali dari karet gelang, dimana setiap anak akan melompat mengikuti ayunan dari tali.

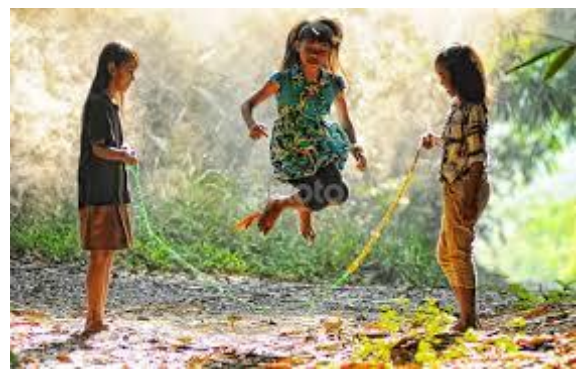

Gambar 2.4. Anak-anak bermain lompat tali

\section{Gobak Sodor}

Permainan yang dilakukan di lapangan, dimana pemainnya dibagi ke dalam dua kelompok, ada kelompok yang bertugas menjaga wilayahnya dengan menghalangi lawan masuk ke wilayahnya, dan ada kelompok yang akan berusaha masuk ke wilayah batas lawannya.

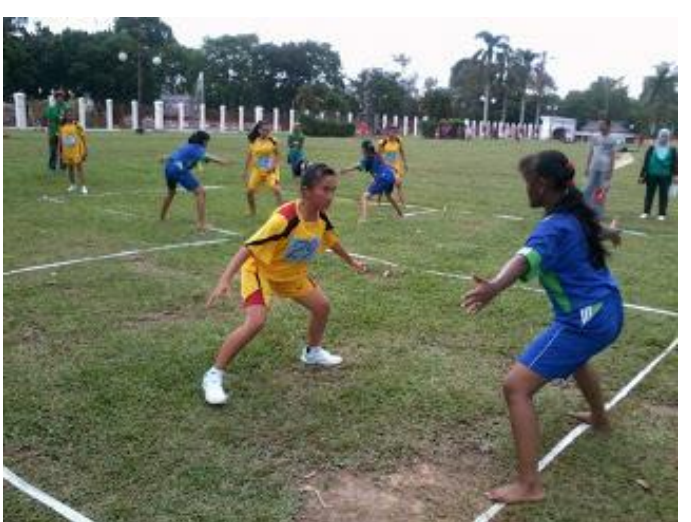

Gambar 2.5. Anak-anak bermain Gobak Sodor

\section{Main Kelereng/Gundu}

Permainan dengan bola kecil yang biasa disebut kelereng, dimana tiap anak akan berusaha membidik kelereng milik temannya.

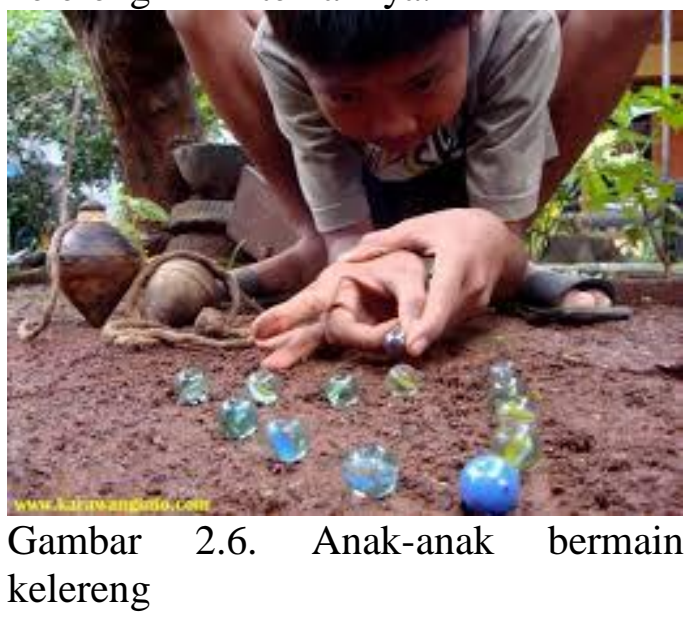

\section{Gasing}

Permainan yang memutarkan batangan pohon/kayu yang dibentuk dan selama berputar kepala gasing harus tetap berada di atas untuk menghantam gasing lawan. Bila kepala gasing berpindah posisi maka pemain akan menelan kekalahan. 


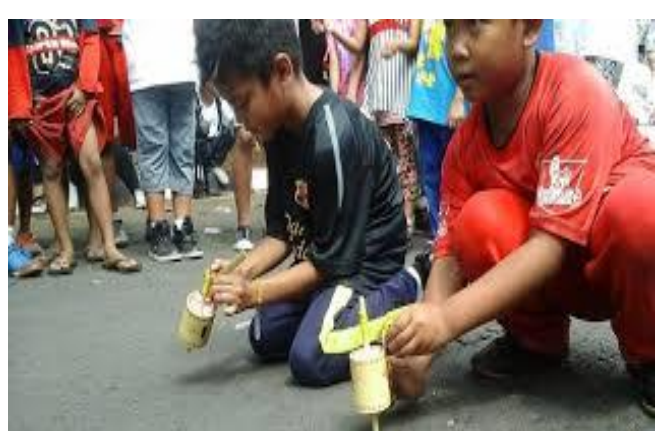

Gambar 2.7. Anak-anak bermain gasing

\section{Permainan Tradisional Anak Indonesia dalam Perangkat Berbasis Android}

Dalam perangkat berbasis Android saat ini sudah dapat dijumpai permainan tradisional anak Indonesia, namun semua aplikasi permainan tradisional tersebut hanya terbatas pada penyampaian informasi ataupun pengenalan. Anak-anak yang belum mengenal atau mengetahui beragam jenis permainan tradisional anak Indonesia dapat menggali lebih dalam informasi tentang tiap jenis permainan tradisional.

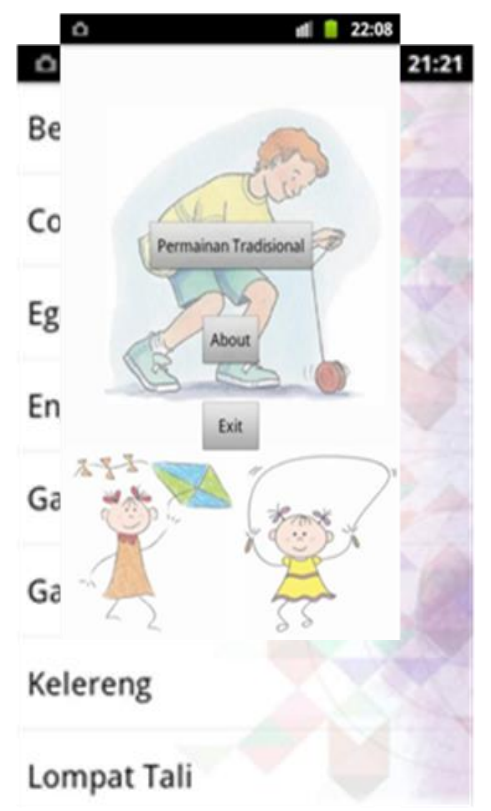

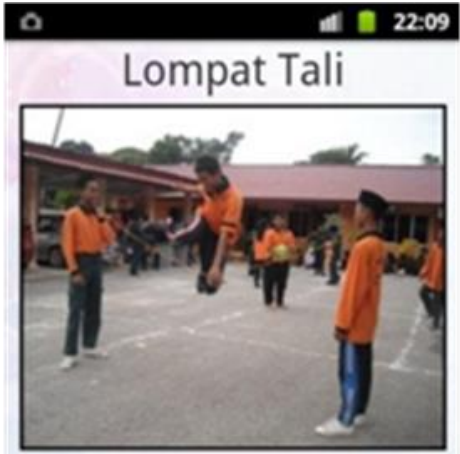

Permainan ini sudah tidak asing lagi tentunya karena permainan lompat tali ini bisa di temukan hampir di seluruh indonesia meskipun dengan nama yang berbeda-beda. Permainan lompat tali ini biasanya identik densan kaum perempuan. Tetapi juga tidak sedikit anak lakj-laki yang ikut bermain.

Cara Bermain:

1. Melompati anyaman karet dengan ketingeian tertentu.

Gambar 2.8. Tampilan salah satu aplikasi permainan tradisional anak Indonesia berbasis Android

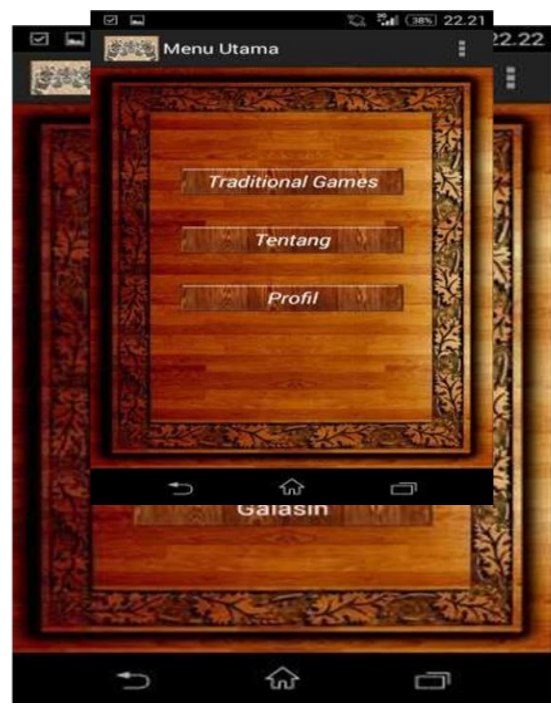

Gambar 2.9. Tampilan salah satu aplikasi permainan tradisional anak Indonesia berbasis Android

Aplikasi permainan tradisional anak Indonesia berbasis Android merupakan salah satu sarana bagi pembuat aplikasi untuk dapat memperkenalkan permainan tradisional anak Indonesia yang sekarang sudah sulit ditemui terutama di daerah perkotaan. Anak-anak yang bemukim di perkotaan, lebih mengenal 
permainan modern yang hanya mengandalkan jempol untuk mengoperasikannya. Budaya dalam permainan modern memang tidak semuanya membawa dampak positif, namun lebih banyak membawa dampak negatif.

Menurut dr.Tjhin Wiguna, $\operatorname{SpKJ}(\mathrm{K})$, dari Divisi Psikiater Anak dan Remaja Departemen Psikiatri Fakultas Kedokteran Universitas Indonesia/ rumah Sakit Ciptomangunkusumo (FKUI/RSCM) Jakarta, bahwa “ harusnya pada usia balita, anak terikat pada orang tua dan lingkungan sekeliling sehingga bisa belajar. Keterikatan pada perangkat berbasis Android akan membatasi kesempatan anak untuk belajar dan berkembang.

Terbatasnya kesempatan untuk belajar, disebabkan perangkat berbasis Android hanya mampu berkomunikasi satu arah, yakni merespon kemauan pengguna dalam hal ini balita. Akibatnya, anak tidak mampu mengenali dan berbagi aneka emosi, misal: simpati, sedih, atau senang. Alhasil, menurut Tjhin, anak kurang mampu merespon apa yang terjadi di sekelilingnya, baik secara emosi maupun verbal. Terbatasnya respon anak akan mengganggu perkembangan kemampuan untuk bergaul dan beradaptasi.

Kerugian lain dari keterikatan dengan perangkat berbasis Android pada anak adalah gangguan pada kemampuan motorik kasar dan halus. Hal ini disebabkan anak hanya melakukan sedikit gerakan untuk menggunakan perangkat berbasis Android.

Dalam masa perkembangannya membentuk psikologi anak yang baik sangat diperlukan untuk membentuk kepribadian anak, dari anak yang masih bayi hingga anak mencapai usia 6-8 tahun. Perkembangan jasmani dan rohani mulai mengarah sempurna. Mengenal lebih banyak teman dan lingkungan sosial yang lebih luas, sehingga peranan sosialnya semakin berkembang. Ingin mengetahui segala sesuatu di sekitarnya sehingga bertambah perjalanannya. Semua pengalaman itu akan membantu dan mempengaruhi proses perkembangan berpikir anak.

\section{Kesimpulan}

Dari uraian di atas, penulis menggaris bawahi suatu alur yang hilang dalam permainan tradisional anak Indonesia dalam perangkat berbasis Android yaitu :

1. Perangkat berbasis Android mampu memperkenalkan sejarah dan cara bermain dalam beragam permainan tradisional anak Indonesia namun saat ini belum mampu menggantikan manfaat bermain bagi tumbuh kembang anak Indonesia.

2. Perangkat berbasis Android mampu memperkenalkan budaya dalam permainan tradisional anak Indonesia namun saat ini belum mampu melestarikan budaya dalam permainan tradisional anak Indonesia.

3. Banyak pendapat yang mengatakan bahwa permainan tradisonal anak Indonesia merupakan warisan nenek moyang, warisan dari para leluhur bangsa Indonesia. Sehingga dengan melestarikan sebagai kebudayaan nenek moyang berarti anak Indonesia mampu melestarikan budaya Indonesia. Namun pewarisan itu sendiri selalu mengalami perubahan sesuai dengan perkembangan zaman dan perkembangan kebudayaan.

4. Penulis berharap kemajuan teknologi informasi ke depannya dapat diimbangi dengan pemikiran untuk mulai mengimplementasi aplikasi permainan yang mampu 
mengembalikan fungsi dan manfaat utama permainan bagi generasi penerus bangsa.

\section{Daftar Pustaka}

Singgih D. Gunarsa,(2013).Dasar dan Teori Perkembangan. Jakarta: PT BPK Gunung Mulia

Tim penyusun Depdikbud. 1997/1998. Pembinaan Nilai Budaya Melalui Permainan Rakyat Daerah IstimewaYogyakarta.Depdikbud: Yogyakarta

Zulkifli L.(2002). Psikologi

Perkembangan.Bandung: PT Remaja Rosdakarya.

\section{Internet}

http://health.kompas.com/read/2013/05 /01/14171091/Kenapa.Balita.Tak .Boleh.Akrab.dengan.Gadget. Di akses 24 Mei 2016 